J Int Neuropsychol Soc. 2009 July ; 15(4): 501-508. doi:10.1017/S1355617709090900.

\title{
Dyslexia: The evolution of a scientific concept
}

\author{
JACK M. FLETCHER \\ Department of Psychology, University of Houston, TMC Annex, Houston, Texas
}

\begin{abstract}
In the past 25 years, scientific understanding of dyslexia and other learning disabilities has seen rapid progress in domains involving definition and classification, neuropsychological correlates, neurobiological factors, and intervention. I discuss this progress, emphasizing the central organizing influence of research and theory on basic academic skills on identification and sampling issues. I also emphasize how neuropsychological approaches to dyslexia have evolved and the importance of an interdisciplinary perspective for understanding dyslexia.
\end{abstract}

\section{Keywords}

Neuropsychology; Learning disorders; Response to intervention; Psychological tests; Magnetic resonance imaging

\section{WHAT IS DYSLEXIA?}

Dyslexia is a reading disorder in children and adults identified in part by difficulties with single-word reading and spelling (Lyon et al., 2003; Pennington, 2009, p. 82). Prevalence estimates range from 6 to $17 \%$ of the school age population depending largely on criteria for the severity of reading difficulties (Fletcher et al., 2007, p. 105). There is male preponderance, with a ratio of about 1.5:1 but lower than historical estimates of about 3-4:1 (Pennington, 2009, p. 45; Rutter et al., 2004). The origins of dyslexia are neurobiological with strong evidence for heritability, but environmental factors also shape and ameliorate risk for dyslexia; it can be prevented in many children with early intervention (Fletcher et al., 2007, pp. 131-149; Pennington, 2009, pp. 49-57).

\section{DEFINITIONS}

Earlier definitions such as that from the World Federation of Neurology identified dyslexia as a disorder of reading in the presence of average intelligence, conventional instruction, and socioeconomic status (Critchley, 1970). Such definitions have been widely criticized because they mostly indicate what dyslexia is not, that is, definition by exclusion, and fail to provide inclusionary criteria (Rutter, 1982). Contemporary definitions have evolved through research so that dyslexia is now often defined according to a definition from the International Dyslexia Association (IDA) as "difficulties with accurate and/or fluent word recognition and by poor spelling and decoding abilities. These difficulties typically result from a deficit in the phonological component of language that is often unexpected in relation to other cognitive abilities and the provision of effective classroom instruction." (Lyon et al., 2003). Note that not only does this definition indicate inclusionary criteria specifying that

Correspondence and reprint requests to: Jack M. Fletcher, Department of Psychology, University of Houston, TMC Annex, 2151 West Holcombe Boulevard, 222 TMC Annex, Houston, Texas 77204-5053. jackfletcher@uh.edu. 
dyslexia is a word-level disorder but also that dyslexia occurs because of a specific cognitive deficit, evidence of adequate classroom instruction, and absence of other disabilities that would explain the reading problem (e.g., intellectual retardation). There is no reference to intelligence quotient (IQ) or socioeconomic status.

I argue that the example of changes in definition represents a fundamental shift in scientific understanding of learning disabilities (LDs) that has occurred over the past 25 years. A major component is the move away from general descriptions of "reading disorders" to specific types of reading problems that may involve (1) decoding single words (dyslexia), (2) the ability to read words and text automatically in the absence of a word reading problem (fluency), or (3) a comprehension problem when decoding and fluency skills are intact. A person with dyslexia typically has problems with all three domains because of the word reading bottleneck, but smaller groups of children experience difficulty primarily with fluency and/or comprehension. This distinction is important because the neuropsychological and neurobiological correlates will vary depending on the nature of the reading problem (Fletcher et al., 2007).

\section{HISTORICAL BACKGROUND: A NEUROPSYCHOLOGICAL PERSPECTIVE}

To understand the evolution of the concept of dyslexia, consider Benton's (1975) review of research on dyslexia. At this time, neuropsychologists assessed symptoms of brain dysfunction to understand the etiology of dyslexia as a prerequisite to treatment. Thus, Benton (1975) identified eight neuropsychological correlates of dyslexia, including deficits in visuoperceptual and audioperceptual functions, directional sense, right-left discrimination, finger recognition, and generalized language deficiencies. He identified putative brain mechanisms for reading disorders involving focal maldevelopment of the parietal lobes or overall organization of the cerebral hemispheres but lamented the definition issues and the apparent heterogeneity of the disorder.

Reflecting the World Federation of Neurology definition, Benton (1975) noted that criteria for dyslexia and other LDs were vague and exclusionary. Children and adults could be identified with dyslexia or LD based on a reading problem, a neuropsychological deficit, soft neurological signs, clumsiness, electrophysiological deficits, and even behavior problems, reflecting the historical origin of the concept of LD in neurologically based behavioral difficulties epitomized by the hyperactive child (Rutter, 1982). In addition, others observed that while directly training neurological or perceptual processes was popular, specific programs rarely showed transfer to academic skill development (Mann, 1979). Researchers became increasingly aware of the heterogeneity of LDs (Rourke, 1975) and the fact that univariate comparisons showed significant differences on almost every neuropsychological variable (Doehring, 1978).

These observations helped the field move toward a focus on definition and classification issues in order to understand the etiology of dyslexia. In 1985, the National Institute of Child Health and Human Development (NICHD) began a research program initially addressing definition issues from an interdisciplinary perspective in order to understand the causes of dyslexia (Lyon, 1999). Because of these efforts, I suggest that research has evolved to a point where there is a good understanding of how to define dyslexia, and also of the neuropsychological and behavioral correlates, and an emerging understanding of the neurobiological and environmental factors that cause this complex disorder. Sadly, this work has not penetrated to the lay public, and children continue to be identified with dyslexia for a multitude of associated signs and receive treatments that have little efficacy and deviate from scientific understanding of the disorder. 


\section{A COMPREHENSIVE MODEL OF DYSLEXIA AND OTHER LDS}

Figure 1 provides a schematic overview from Fletcher et al. (2007, pp. 2-3) of the different components I believe are necessary for a comprehensive scientific understanding of dyslexia. For all LDs, the model assumes that an achievement problem is a necessary but not a sufficient component of identification. For dyslexia, the single-word reading difficulty should be a key component of identification (Pennington, 2009, p. 82). If identification does not include a word-level problem, the sample becomes very heterogeneous because the cognitive and neurobiological correlates vary with different components of reading (Fletcher et al., 2007, chap. 5-7). The recognition of dyslexia as a word-level problem and identification into samples on that basis may be responsible for many of the advances in research. To illustrate, I briefly discuss what is understood about identification, cognitive correlates, neurobiological factors, and environmental factors in relation to the most common LD, dyslexia.

\section{DEFINITION AND CLASSIFICATION: THE CENTRAL ROLE OF ACADEMIC DEFICITS}

\section{IQ-Achievement Discrepancy}

Classification research aims to identify components of a disorder that are essential for identification. At one point, it was widely believed that academic problems needed to be referenced to IQ, epitomized by the U.S. Federal regulatory definition of LD as a discrepancy in IQ and achievement (U.S. Office of Education, 1977). This approach stemmed from the Rutter and Yule (1975) Isle of Wight epidemiological studies, in which the presence of an IQ-achievement discrepancy differentiated children with "specific reading retardation" from those who were "general backwards readers." However, Rutter and Yule (1975) did not exclude children with mental retardation or brain injury. The average IQ of the group with general reading backwardness was about $2 S D$ s below the mean, which raises issues about the extrapolation of this concept of reading backwardness to children with IQ scores not associated with intellectual retardation. Little evidence has emerged showing that poor readers who would not be considered intellectually retarded can be meaningfully differentiated based on an IQ-achievement discrepancy classification in cognitive skills (Hoskyn \& Swanson, 2000; Stuebing et al., 2002), prognosis (Francis et al., 1996), and intervention response (Stuebing et al., in press). Partly in response to this body of research, Congress changed Federal statutes so that schools could not be required to use IQ tests for identification of LD (U.S. Department of Education, 2004).

\section{Dimensional Nature of Dyslexia}

Unlike Rutter and Yule (1975), international epidemiological studies have shown that dyslexia is dimensional and exists as the lower end of a normal continuum of reading ability (Jorm et al., 1986; Rodgers, 1983; Shaywitz et al., 1992). Deciding reliably where on this continuum a disability resides is inherently arbitrary, which is why prevalence estimates range so broadly (Francis et al., 2005; Pennington, 2009, p. 47). More importantly, since dyslexia does not represent a qualitatively distinct disorder, there is no need for separate theories of success and failure in learning to read. Research can link directly to normative development, and the dimensional nature encourages a focus on reading as a cardinal attribute. Such an approach fueled research in dyslexia and other domains of LD (Shavelson \& Towne, 2002, pp. 38-41).

\section{Cognitive Correlates}

No single theory and body of research has had more impact on the concept of dyslexia and LD than scientific understanding of how children develop word recognition skills. 
Representing what Stanovich (2000) described as a "big idea" in science, this research had far-reaching implications for understanding and teaching children who are typically developing and who struggle to read. In contrast to earlier neuropsychological approaches (Benton, 1975), it highlighted why a theory of dyslexia must explain the reading problem and that a focus on associated features was likely to be less productive. Efforts to explain the reading problem in people with dyslexia have been very productive.

The major breakthrough was the discovery that the link between oral language and written language resided in the phonological structure of speech (Shavelson \& Towne, 2002, pp. 38-41). In the late 1960s, researchers at the Haskins Laboratories were developing machines that would help people with deafness communicate. The investigators realized that speech was processed as a segmented signal, although the speaker may not recognize this segmented structure because speech sounds are merged together during production. So words like "dog," which actually has three segments at a phonemic level, are heard as one coarticulated unit. These observations led to a major theory of speech processing and then of reading, where it was hypothesized that the segmented units of speech are also represented in print at a phonemic level through the alphabet (Liberman \& Shankweiler, 1991). Thus, written language is scaffolded upon oral language, and literacy is a product of evolutionarily established human capabilities for speech (Liberman, 1997). These findings anchored conceptualizations of reading disabilities in specific reading processes and language (Pennington, 2009, pp. 57-62; Vellutino et al., 2004).

There are other cognitive and neuropsychological skills linked to dyslexia, and this relation of phonological awareness and word recognition may not fully explain why children with dyslexia have other (often comorbid) language and attention problems, math, motor, and other difficulties (Pennington, 2009, p. 62). As Figure 2 shows, children with dyslexia (or math disability) may differ significantly from typically developing children on almost any neuropsychological variable if the sample is large enough. If children with comorbid attention deficit hyperactivity disorder are included in the dyslexia or math disability samples, the differences are much larger (Fletcher et al., 2007, pp. 56-57). There are theories involving the cerebellum, low-level vision and speech processing, and other domains (Fletcher et al., 2007, pp. 96-98; Pennington, 2009, pp. 62-66; Vellutino et al., 2004, pp. 7-10). Harkening back to Doehring (1978), univariate theories abound and much depends on identification criteria. It is common to take a cognitive deficit and extrapolate to a brain mechanism underlying the neuropsychological deficit as well as the reading disorder, which often, as in Benton's (1975) time, leads to the construction of reading theories to fit the neuropsychological data. None of these hypotheses has had much success in explaining or treating the word reading problem (Vellutino et al., 2004, pp. 7-10).

It is possible that some of these theories could explain other aspects of a broader phenotype (e.g., fluency problems) or even why some children with dyslexia have problems in the motor system unrelated to reading (Denckla et al., 1985). However, phonological awareness, along with rapid naming and verbal working memory, is most consistently linked to the word reading disorder regardless of comorbidities (Willcutt et al., 2005), thus helping to explain the word reading problem that is the cardinal feature of dyslexia. These skills would be at the top of Benton's (1975) list of neuropsychological correlates in 2009. In my opinion, identifying children with word-level problems and assuming dimensionality have proven remarkably fruitful for functional neuroimaging (Fletcher et al., 2007, pp. 112-123) and genetic studies (Grigorenko \& Naples, in press). 


\section{NEUROBIOLOGICAL FACTORS}

\section{Brain}

Studies of brain structure in dyslexia, whether through the small number of postmortem studies or structural imaging studies, have implicated a variety of regions of the brain and cerebellum. The most consistent evidence identifies perisylvian language areas as either small or symmetric relative to controls (Pennington, 2009, p. 53). The lack of consistency reflects the small heterogeneous samples that characterize many of these studies (Fletcher et al., 2007, pp. 108-112). Future studies with larger samples and newer imaging modalities, such as diffusion tensor imaging, may lead to a more consistent set of findings (Ben-Shachar et al., 2007).

In contrast, functional neuroimaging studies of different components of reading in children defined with dyslexia show reliable differences in activation relative to proficient readers (Price \& McCrory, 2005, p. 49). There is no cognitive skill more frequently imaged than word recognition, and the neural networks that support word reading are fairly well established. These systems involve bilateral basal temporal regions for feature recognition, the angular gyrus, middle and superior temporal gyri for cross-modal integration and phonological processing predominantly in the left hemisphere, and frontal regions if production is involved. The involvement of these and other brain regions will vary depending on task characteristics and level of proficiency (Price \& McCrory, 2005, pp. 475483). In dyslexia, different functional imaging studies converge in identifying underactivation of the posterior regions in children with dyslexia and sometimes hyperactivity in the frontal regions. Moreover, these posterior differences predominantly normalize when intervention is successful (Meyler et al., 2008; Shaywitz et al., 2004; Simos et al., 2002), although there is variation across studies.

Figure 3 shows an example of common findings from a yearlong intervention of Grade 5 poor readers before and after an intense reading intervention (Meyler et al., 2008). The children were identified with a reading fluency task, so there is probably more heterogeneity compared to selection with a word reading test. Using functional magnetic resonance imaging and a sentence comprehension activation task, the temporal-parietal areas were underactivated in poor readers at baseline but normalized with improved reading after intervention. Interestingly, unlike Shaywitz et al. (2004), the occipital-temporal regions were not underactivated at baseline and did not show major shifts with intervention. Differences in the activation task and selection criteria, which involved word reading in Shaywitz et al. (2004), likely explain the differences in the two studies. Although there are now about 15 intervention-imaging studies showing convergence around normalizing changes in the neural network supporting word recognition as well as apparent compensatory changes (Fletcher et al., 2007, pp. 117-123), the idea that the neural systems underlying word recognition are malleable is most important. Learning to read literally rewrites the organization of the brain. Since we are not born to read, in contrast to speaking, instruction of some sort is necessary to engage these regions of the brain (Liberman, 1997). For some people, more instruction is needed; for others, instruction will never result in reading skills in the average range.

\section{Genes}

With a focus on specific reading processes, genetic loci associated with poor reading have been replicated in many laboratories around the world. At this point, there are nine regions of the genome and six candidate genes under active investigation (Grigorenko \& Naples, in press). Dyslexia clearly has a heritable component that accounts for about $50-80 \%$ of the variance in reading outcomes. However, no major gene effects have been identified, and the 
contributions reflect multiple small effects. There are multiple genes involved in good and poor reading, with no dyslexia-specific genes (Pennington, 2009, pp. 49-52). However, there is also evidence that the genetic correlation for reading increases significantly with schooling (Samuelsson et al., 2007), highlighting the importance of early intervention.

\section{ENVIRONMENTAL FACTORS}

Factors related to poverty and the family's orientation to literacy represent risk factors for dyslexia. The impact of poverty on language and achievement is clearly established, but even in middle-class families where one or more parents are poor readers, literacy-related activities are often not emphasized (Pennington et al., 2009). However, another critically important factor is instruction. At a classroom level, the quality of reading instruction varies considerably. Meta-analytic reviews like the National Reading Panel Report (NICHD, 2000) have shown that children at risk for reading problems require instructional approaches that are more explicit, meaning that translation of the alphabetic principle into instruction through methods like phonics needs to be intentionally laid out in an organized fashion in order for at-risk children to make explicit what is inherently an implicit understanding of the relation of print and sound (Rayner et al., 2002). In addition, only teaching phonics reduces transfer to other domains of reading, so more comprehensive approaches that also include reading practice to build fluency and explicit teaching of comprehension strategies and vocabulary usually result in higher levels of overall reading proficiency (Stuebing et al., 2008). Better outcomes are associated with earlier intervention, primarily because children fall far behind their peers when they are not able to access print (Torgesen et al., 2001).

The past decade has seen an explosion in research evaluating reading interventions using designs from which stronger causal inferences can be made (Fletcher et al., 2007, pp. 129162). These studies include evaluations of classroom programs, prevention programs, and remedial programs. While still evolving, this research had major impact on the reauthorization of the Individuals With Disabilities Education Act (IDEA in 2004), which included components permitting school districts to move away from the IQ discrepancy model of identification adopted in 1977 (U.S. Office of Education, 1977) and to implement models that focus in part on intervention response. Specifically, the regulations permit either a response to intervention process or an alternative discrepancy models depending on state guidelines (U.S. Department of Education, 2006, p. 46786):

(i) The child does not make sufficient progress to meet age or State-approved grade-level standards in one or more of the [8 domains of achievement] when using a process based on the child's response to scientific, research-based intervention ...; or

(ii) The child exhibits a pattern of strengths and weaknesses in performance, achievement, or both, relative to age, State-approved grade-level standards, or intellectual development, that is determined by the group to be relevant to the identification of a specific learning disability, using appropriate assessments ...

Response to intervention models link prevention and remedial interventions through multitiered approaches to service delivery in schools, including (1) universal screening for reading (and math and behavior problems), (2) monitoring progress of at-risk children through frequent assessment probes using reading fluency tasks, and (3) providing increasingly intense intervention based on the child's progress (Fletcher \& Vaughn, 2009). The data on intervention response can be used as a component of the identification process for special education, with IDEA (2004) still requiring a comprehensive evaluation that uses multiple sources of information. Recognizing that many children included in special education may be instructional casualties because of the need for better instruction, IDEA 
(2004) also requires evidence of adequate instruction in reading and math as one of these sources.

\section{CONCLUSIONS: THE IMPORTANCE OF INTRACTABILITY}

Returning to the issue of definition, the intervention research helps clarify what else needs to be added to the definition of LDs like dyslexia, namely evidence of adequate instructional opportunity (Fuchs \& Fuchs, 1998). Many children are at risk for dyslexia because of neurobiological and environmental factors, and even those with genetic risk may not manifest the disorder depending on their home environments and quality of instruction (Pennington et al., 2009). As the IDA definition of dyslexia suggests (Lyon et al., 2003), evidence of adequate instruction is another inclusionary criterion that should be included in the definition of dyslexia and other LDs.

Research in the future should focus on children whose single-word deficits are resistant to intervention, with comparisons to typical and at-risk children along the domains in Figure 1. Such studies may shed new light on the neuropsychological and neurobiological factors of historical interest to neuropsychologists. However, views in which brain dysfunction is directly assessed with neuropsychological tests (Benton, 1975;Rourke, 1975) may need to shift because of newer conceptualizations of dyslexia as a heritable disorder that makes the brain at risk and that emerges due to interactions of neurobiological and environmental factors. The use of neuropsychological tests as a central part of identification has not been well justified, given the classification research that has been completed, which simplifies identification. In addition, there is little evidence that such assessments help plan treatment or that other forms of intervention based on neuropsychological assessment improve academic or adaptive outcomes. Despite claims to the contrary (Hale et al., 2008), there is little evidence of Aptitude $\times$ Treatment interactions for cognitive/neuropsychological skills at the level of treatment or aptitude (Reschly \& Tilly, 1999, pp. 28-29). The strongest evidence of Aptitude $\times$ Treatment interactions is when strengths and weaknesses in academic skills are used to provide differential instruction (e.g., Connor et al., 2007).

I am not encouraging acceptance of the null hypothesis but rather calling the neuropsychological research and professional communities to action. We need research that supports the assessments we do. More importantly, as neuropsychologists, we need to fully understand the interdisciplinary body of research that has changed scientific understanding of dyslexia and LD and adds to the research base outlined in Figure 1, which is most complete for dyslexia and rapidly emerging in other LDs. We need to prioritize intervention and link our scientific and professional practices to the goal of enhancing adaptive functions in children with or at risk for LDs. Neuropsychology has been at the forefront of the evolution of dyslexia as a scientific concept and should continue to make contributions by questioning what we know and working at the edges of disciplinary boundaries.

\section{Acknowledgments}

This study is supported in part by a grant from the NICHD, 1 P50 HD052117, Texas Center for Learning Disabilities.

\section{REFERENCES}

Ben-Shachar M, Dougherty RF, Wandell BA. White matter pathways in reading. Current Opinion in Neurobiology. 2007; 17:258-270. [PubMed: 17379499]

Benton, AL. Development dyslexia: Neurological aspects. In: Friedlander, WJ., editor. Advances in neurology. Vol. Vol. 7. Raven Press; New York: 1975. p. 1-47. 
Connor CM, Morrison FJ, Fishman BJ, Schatschneider C, Underwood P. Algorithm-guided individualized reading instruction. Science. 2007; 315:464-465. [PubMed: 17255498]

Critchley, M. The dyslexic child. Charles C. Thomas; Springfield, IL: 1970.

Denckla MB, Rudel MB, Krieger RG, Chapman J. Motor proficiency in dyslexic children with and without attentional disorders. Archives of Neurology. 1985; 42:228-231. [PubMed: 3977652]

Doehring, DG. The tangled web of behavioral research on developmental dyslexia. In: Benton, AL.; Pearl, D., editors. Dyslexia: An appraisal of current research. Oxford; New York: 1978. p. 123-137.

Fletcher, JM.; Lyon, GR.; Fuchs, LS.; Barnes, MA. Learning disabilities: From identification to intervention. Guilford; New York: 2007.

Fletcher JM, Vaughn S. Response to intervention: Preventing and remediating academic deficits. Child Development and Perspectives. 2009; 3:30-37.

Francis DJ, Fletcher JM, Stuebing KK, Lyon GR, Shaywitz BA, Shaywitz SE. Psychometric approaches to the identification of LD: IQ and achievement scores are not sufficient. Journal of Learning Disabilities. 2005; 38:98-108. [PubMed: 15813593]

Francis DJ, Shaywitz SE, Stuebing KK, Shaywitz BA, Fletcher JM. Developmental lag versus deficit models of reading disability: A longitudinal, individual growth curves analysis. Journal of Educational Psychology. 1996; 88:3-17.

Fuchs LS, Fuchs D. Treatment validity: A unifying concept for reconceptualizing the identification of learning disabilities. Learning Disabilities Research and Practice. 1998; 13:204-219.

Grigorenko, EL.; Naples, AJ. The devil is in the details: Decoding the genetics of reading. In: McCardle, P.; Pugh, K., editors. Helping children learn to read: Current issues and new directions in the integration of cognition, neurobiology and genetics of reading and dyslexia. Psychological Press; NewYork: in press

Hale, JB.; Fiorello, CA.; Miller, JA.; Wenrich, K.; Teodori, AM.; Henzel, J. WISC-IV assessment and intervention strategies for children with specific learning disabilities. In: Prifitera, A.; Saklofske, DH.; Weiss, LG., editors. WISC-IV clinical assessment and intervention. 2nd ed.. Elsevier; New York: 2008. p. 109-171.

Hoskyn M, Swanson HL. Cognitive processing of low achievers and children with reading disabilities: A selective meta-analytic review of the published literature. School Psychology Review. 2000; 29:102-119.

Jorm AF, Share DL, MacLean R, Matthews R. Cognitive factors at school entry predictive of specific reading retardation and general reading backwardness: A research note. Journal of Child Psychology and Psychiatry and Allied Disciplines. 1986; 27:45-54.

Liberman, AL. How theories of speech affect research in reading and writing. In: Blachman, BA., editor. Foundations of reading acquisition and dyslexia: Implications for early intervention. Lawrence Erlbaum; Mahwah, NJ: 1997. p. 3-19.

Liberman, IY.; Shankweiler, D. Phonology and beginning reading: A tutorial. In: Rieben, L.; Perfetti, CA., editors. Learning to read: Basic research and its implications. Erlbaum; Hillsdale, NJ: 1991. p. 3-17.

Lyon GR. In celebration of science in the study of reading development, reading difficulties, and reading instruction: The NICHD perspective. Issues in Education: Contributions from Educational Psychology. 1999; 5:85-115.

Lyon GR, Shaywitz SE, Shaywitz BA. A definition of dyslexia. Annals of Dyslexia. 2003; 53:1-14.

Mann, L. On the trail of process. Grune \& Stratton; New York: 1979.

Meyler A, Keller TA, Cherkassky VL, Gabrieli JDE, Just MA. Modifying the brain activation of poor readers during sentence comprehension with extended remedial instruction: A longitudinal study of neuroplasticity. Neuropsychologia. 2008; 46:2580-2592. [PubMed: 18495180]

National Institute of Child Health and Human Development. Report of the National Reading Panel. Teaching children to read: An evidence-based assessment of the scientific research literature on reading and its implications for reading instruction. Washington, DC: U.S. Government Printing Office; 2000. NIH Publication No. 00-4769

Pennington, BF. Diagnosing learning disorders: A neuropsychological framework. 2nd ed.. Guilford Press; New York: 2009. 
Pennington BF, McGrath LM, Rosenberg J, Barnard H, Smith SD, Willcutt EG, Friend A, DeFries JC, Olson RK. Gene $\times$ environment interactions in reading disability and attention-deficit/ hyperactivity disorder. Developmental Psychology. 2009; 45:77-89. [PubMed: 19209992]

Price, CJ.; McCrory, E. Functional brain imaging studies of skilled reading and developmental dyslexia. In: Snowling, MJ.; Hulme, C., editors. The science of reading: A handbook. Blackwell Publishing; Oxford, UK: 2005. p. 473-496.

Rayner K, Foorman BR, Perfetti CA, Pesetsky D, Seidenberg MS. How psychological science informs the teaching of reading. Psychological Science in the Public Interest. 2002; 2:31-74.

Reschly, DJ.; Tilly, WD. Reform trends and system design alternatives. In: Reschly, D.; Tilly, W.; Grimes, J., editors. Special education in transition. Sopris West; Longmont, CO: 1999. p. 19-48.

Rodgers B. The identification and prevalence of specific reading retardation. The British Journal of Educational Psychology. 1983; 53(3):369-373. [PubMed: 6652037]

Rourke BP. Brain-behavior relationships in children with learning disabilities: A research program. The American Psychologist. 1975; 30:911-920. [PubMed: 1180421]

Rutter M. Syndromes attributed to "minimal brain dys-function" in childhood. The American Journal of Psychiatry. 1982; 139:21-33. [PubMed: 6119908]

Rutter M, Caspi A, Fergusson D, Horwood LJ, Goodman R, Maughn B, Moffitt TE, Meltzer H, Carroll J. Sex differences in developmental reading disability. New findings from 4 epidemiological studies. The Journal of the American Medical Association. 2004; 291:2007-2012.

Rutter M, Yule W. The concept of specific reading retardation. Journal of Child Psychology and Psychiatry and Allied Disciplines. 1975; 16(3):181-197.

Samuelsson S, Olson R, Wadsworth S, Corley R, DeFries J, Willcutt E, Hulsander J, Byrne B. Gene and environmental influences on prereading skills and early reading and spelling development in the United States, Australia, and Scandinavia. Reading and Writing. 2007; 20:51-71.

Shavelson, R.; Towne, L. Science and education. National Academy of Sciences; Washington, DC: 2002.

Shaywitz BA, Shaywitz SE, Blachman BA, Pugh KR, Fulbright RK, Skudlarski P, Mencl WE, Constable RT, Holahan JM, Marchione KE, Fletcher JM, Lyon GR, Gore JC. Development of left occipitotemporal systems for skilled reading children after a phonologically-based intervention. Biological Psychiatry. 2004; 55:926-933. [PubMed: 15110736]

Shaywitz SE, Escobar MD, Shaywitz BA, Fletcher JM, Makuch R. Evidence that dyslexia may represent the lower tail of a normal distribution of reading ability. The New England Journal of Medicine. 1992; 326:145-150. [PubMed: 1727544]

Simos PG, Fletcher JM, Bergman E, Breier JI, Foorman BR, Castillo EM, Fitzgerald M, Papanicolaou AC. Dyslexia-specific brain activation profile becomes normal following successful remedial training. Neurology. 2002; 58:1203-1213. [PubMed: 11971088]

Stanovich, KE. Progress in understanding reading. Guilford; New York: 2000.

Stuebing KK, Barth AE, Cirino PT, Francis DJ, Fletcher JM. A response to recent re-analyses of the National Reading Panel Report: Effects of systematic phonics instruction are practically significant. Journal of Educational Psychology. 2008; 100:123-134. [PubMed: 21258576]

Stuebing KK, Barth AE, Fletcher JM. IQ is not strongly related to response to reading instruction: A meta-analytic interpretation. Exceptional Children. inpress.

Stuebing KK, Fletcher JM, LeDoux JM, Lyon GR, Shaywitz SE, Shaywitz BA. Validity of IQdiscrepancy classifications of reading disabilities: A meta-analysis. American Educational Research Journal. 2002; 39(2):469-518.

Torgesen JK, Alexander AW, Wagner RK, Rashotte CA, Voeller KKS, Conway T. Intensive remedial instruction for children with severe reading disabilities: Immediate and long-term outcomes from two instructional approaches. Journal of Learning Disabilities. 2001; 34:33-58. [PubMed: 15497271]

U.S. Department of Education. Individuals with Disabilities Improvement Act of 2004, Public Law. 108-466; Federal Register. 2004. p. 35802-35803.

U.S. Department of Education. 34 CFR Parts 300 and 301. Assistance to states for the education of children with disabilities and preschool grants for children with disabilities final rule; Federal Register. 2006. p. 46590-46845. 
U.S. Office of Education. Assistance to states for education for handicapped children: Procedures for evaluating specific learning disabilities; Federal Register. 1977. p. G1082-G1085.

Vellutino FR, Fletcher JM, Snowling MJ, Scanlon DM. Specific reading disability (dyslexia): What have we learned in the past four decades? Journal of Child Psychiatry and Psychology and Allied Disciplines. 2004; 45:2-40.

Willcutt EG, Pennington BP, Olson RK, Chhabildas N, Huslander J. Neuropsychological analyses of comorbidity between reading disability and attention deficit hyperactivity disorder: In search or the common deficit. Developmental Neuropsychology. 2005; 27:35-78. [PubMed: 15737942] 


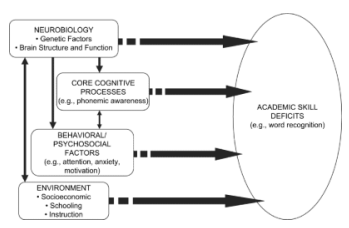

Fig. 1.

Framework representing different sources of variability that influence academic outcomes in children with LDs. From Fletcher et al. (2007, p. 3). Reprinted with permission. 


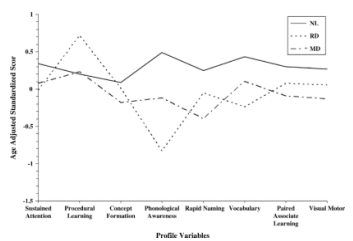

Fig. 2.

Neuropsychological profiles across different cognitive tests for children who are only impaired in word reading (RD) and in computational math (MD) relative to typical achievers (NL). The groups differ in shape and elevation, suggesting three distinct groups. From Fletcher et al. (2007, p. 46). Reprinted with permission. 


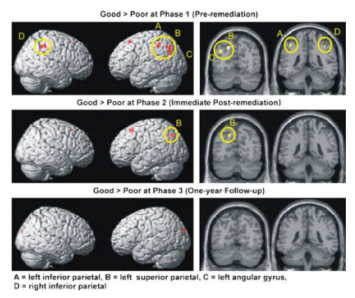

Fig. 3.

Changes in brain activation for students with reading difficulties before a yearlong intervention, at posttest, and after a 1-year follow-up. From Meyler et al. (2008). Reprinted with permission. A, left inferior parietal; B, left superior parietal; C, left angular gyrus; D, right inferior parietal. 